\title{
Proton Exchange Membrane Fuel Cell Cathode Contamination - Acetylene
}

\author{
Y. Zhai*, Jean St-Pierre
}

Hawaii Natural Energy Institute, University of Hawaii, Honolulu, Hawaii 96822, USA

\begin{abstract}
Acetylene adsorption on PEMFC electrodes and contamination in single cells are investigated with $300 \mathrm{ppm}$ acetylene at a cathode held at $80{ }^{\circ} \mathrm{C}$. The results of adsorption experiments suggest that acetylene adsorbs readily on electrodes and is reduced to ethylene and ethane under an open circuit potential of $\mathrm{H}_{2} / \mathrm{N}_{2}$, as the adsorbates can be electro-oxidized at high potentials. The cell voltage response shows that $300 \mathrm{ppm}$ acetylene results in a cell performance loss of approximately $88 \%$. The voltage degradation curve is divided into two stages by an inflection point, which suggests that potential-dependent processes are involved in acetylene poisoning. These potential-dependent processes may include acetylene oxidation and reduction as well as accumulation of intermediates on the electrode surface. Electrochemical impedance spectroscopy analysis suggests that acetylene affects the oxygen reduction reaction and may also affect mass transport processes. Acetylene also may be reduced in the steady poisoning state of the operating cell. After neat air operation, the cyclic voltammetry results imply that the cathode catalyst surface is almost completely restored, with no contaminant residues remaining in the MEA. Linear scanning voltammetry measurements show no change in hydrogen crossover caused by contamination, and polarization curves confirm complete recovery of cell performance.
\end{abstract}

Keywords: PEM Fuel Cell, Performance Degradation, Acetylene Contamination, Oxygen reduction reaction, Electrochemical Impedance Spectroscopy, Cyclic Voltammetry.

*Corresponding Author, Tel.: 18085931714; fax: 18085931719; E-mail: yunfeng@ hawaii.edu 


\section{Introduction}

Proton exchange membrane fuel cells (PEMFCs) are considered to be one of the most promising clean energy conversion technologies. Currently, platinum (Pt) is the only commercially available as well as the most effective electrochemical catalyst for the oxygen reduction reaction (ORR), the key reaction of fuel cell processes $[1,2]$. The Pt ORR catalyst is also active towards most organic compounds. These compounds can adsorb and react on the Pt surface and compete with the ORR [3]. Unfortunately, there are over 200 airborne pollutants, most of which are volatile organic compounds (VOCs) that can be introduced into the PEMFC cathode during air feeding [4-8]. In the past few decades, only a few organic air pollutants have been investigated as contaminants in PEMFCs [9-11], and the results have shown that these contaminants have a significant effect on performance. Recently, our group attempted to determine the overall impact of airborne pollutants on PEMFC performance. By considering functionality, reactivity, atmospheric concentrations, literature reports, industry suggestions, and toxicity to humans, twenty-one contaminants were selected from more than 150 airborne and indoor pollutants detected by Environmental Protection Agency (EPA) monitoring $[8,12]$. The single cell performance response to each of these 21 contaminants was investigated preliminarily under operating conditions that accelerated contamination [13]. Acetylene, $\mathrm{C}_{2} \mathrm{H}_{2}$, one of the most critical contaminants, was found to degrade cell performance by more than $50 \%$.

Acetylene, typically used as a welding fuel and as a precursor molecule in chemical synthesis, is representative of alkyne airborne contaminants. Acetylene in the atmosphere originates almost exclusively from anthropogenic sources, including manufacturing and end-use plant emissions, fossil and biofuel combustion exhausts, and biomass burning [14]. The acetylene concentration in an urban atmosphere is typically up to 0.1 part per million by volume (ppmv) [8]. A diffusion model predicts acetylene concentrations up to 5.5 ( $1 \mathrm{~h}$ average) and $3 \mathrm{ppmv}(24 \mathrm{~h}$ average) near an acetylene plant [14]. The chemical/electrochemical adsorption/reactions of $\mathrm{C}_{2} \mathrm{H}_{2}$ on Pt have been studied extensively for the removal of unburned hydrocarbons from exhaust streams [15-20]. The adsorption of acetylene on a Pt surface can block 2.1 Pt sites per adsorbed species [19]. The conversion of acetylene on Pt surfaces depends on the potential and temperature: at a potential lower than $0.2 \mathrm{~V}$ vs reversible hydrogen electrode (RHE), acetylene is reduced to ethylene and ethane on a Pt surface in a sulfuric 
acid solution; at a potential higher than $0.70 \mathrm{~V}$ vs RHE, acetylene is oxidized to $\mathrm{CO}_{2}$ [19]. Acetylene reactions also compete with the adsorption of oxygen: in the presence of oxygen, acetylene on $\operatorname{Pt}(111)$ reacts with surface oxygen to form $\mathrm{CO}$, which subsequently either desorbs or is further oxidized to $\mathrm{CO}_{2}$, the main oxidation product in the $330-420 \mathrm{~K}$ temperature range [15]. A polymeric surface species may also form on the electrode: for example, the cyclotrimerization or polymerization of acetylene on $\mathrm{Pt} / \mathrm{Al}_{2} \mathrm{O}_{3}$ leads to benzene $[17,19]$. An ex-situ rotating ring disk electrode (RRDE) study showed that acetylene adsorption inhibited the ORR and assisted the ORR reaction pathway, resulting in a shift to 2-electron series reactions from a 4-electron direct reaction [21]. These results provide insight into the probable effect of acetylene contamination on PEMFCs. However, PEMFC contamination tests have not been reported.

In this study, the adsorption of acetylene on MEA electrodes was studied by exposure to acetylene in $\mathrm{N}_{2}$ and cyclic voltammetry (CV). Accelerated acetylene contamination in a single cell was investigated under constant current operation with acetylene in the cathode. Electrochemical impedance spectroscopy (EIS), $\mathrm{H}_{2}$ crossover measurements by liner sweep voltammetry (LSV) and polarization (VI) curve measurements were performed to obtain an understanding of the effects of acetylene contamination on PEMFCs. The electrochemical characterization results are analyzed and discussed in detail.

\section{Experimental}

Experiments were conducted at FCATS ${ }^{\mathrm{TM}}$ G050 series test stations (Green Light Power Technologies Inc.) with a custom-made $50 \mathrm{~cm}^{2}$ single cell. The anode flow-field was a double channel serpentine, and the cathode flow-field was a triple channel serpentine. MEAs used for acetylene contamination tests were purchased from Gore (GORE® PRIMEA® M715 catalyst coated membrane) and had a Pt loading of $0.4 \mathrm{mg} \mathrm{Pt} \mathrm{cm}{ }^{-2}$ on each side. The cells were assembled with $25 \mathrm{BC}$ gas diffusion layers (GDL, SGL Tech.) at both the anode and the cathode. The operating conditions at the anode/cathode were as follows: 100/50\% relative humidity (RH) and a flow rate of $0.697 / 1.659 \mathrm{~L} \mathrm{~min}^{-1}$, which is a $2 / 2$ stoichiometry of $1 \mathrm{~A} \mathrm{~cm}^{-2}$ under $\mathrm{H}_{2} /$ Air operation. The outlet backpressure was $48.3 / 48.3 \mathrm{kPa}$, which corresponds to the pressure of the dry reactants in the cell 
chamber at 1 atm for a cell temperature of $80{ }^{\circ} \mathrm{C}$. The acetylene source was 4040 ppm acetylene in $\mathrm{N}_{2}$ or 4030 ppm acetylene in Air (Matheson Tri-Gas Inc.).

Before the tests, MEAs were activated to obtain steady cell performance. Diagnostics before contamination testing (BOT) included measuring the electrochemical active surface area (ECA) of the electrodes by $\mathrm{CV}$, measuring the $\mathrm{H}_{2}$ crossover of the MEA by LSV, and measuring the cell performance by VI. CV scanning was conducted with $\mathrm{H}_{2} / \mathrm{N}_{2}$ at $35{ }^{\circ} \mathrm{C}$ with fully humidified hydrogen or nitrogen at each side, with flow rates of $0.466 \mathrm{~L} \mathrm{~min}^{-1}$. The hydrogen and nitrogen were supplied to the reference and working electrodes, respectively. A total of 3 scans were performed with a scan rate of $20 \mathrm{mV} \mathrm{s}^{-1}$. The potential range was 0.08 to $1.20 \mathrm{~V}$ vs the hydrogen reference electrode (HRE). The LSV was obtained from 0.08 to $0.40 \mathrm{~V}$ vs HRE with a scan rate of $0.1 \mathrm{mV} \mathrm{s}^{-1}$ under the same conditions used for CV. VI curves with high frequency resistance (HFR, $1 \mathrm{kHz}$ ) were measured from the high current to the open circuit voltage (OCV) with a stabilizing time of 15 min at each current set point under the operating conditions described above with a 2/2 stoichiometry. This activation and diagnostic process ensured comparability and repeatability between the MEAs.

Acetylene adsorption tests were conducted with $300 \mathrm{ppm}$ acetylene in $\mathrm{N}_{2}$ at the cathode side. The MEA was held at the open circuit potential (OCP) of $\mathrm{H}_{2} / \mathrm{N}_{2}$ cell under the conditions described above. Acetylene was injected at approximately $6 \mathrm{~min}$ and stopped at 16, 36 and $66 \mathrm{~min}$. A 0.5, 2, 10 or 30 min pure $\mathrm{N}_{2}$ purge was applied to the contaminated cathode exposed to acetylene for $60 \mathrm{~min}$. Three cycle $\mathrm{CV}$ curves between 0.08 to $1.20 \mathrm{~V}$ were obtained before testing as well as before and after the pure $\mathrm{N}_{2}$ purges with a scan rate of $20 \mathrm{mV} \mathrm{s}^{-1}$.

The acetylene contamination was investigated by applying $300 \mathrm{ppm}$ acetylene in air at the cathode side with a constant current density of $1 \mathrm{~A} \mathrm{~cm}^{-2}$. The three phases of operation included 5 hrs pre-poisoning with neat air, 5 hrs poisoning with acetylene at the cathode, and $10 \mathrm{hrs}$ self-induced performance recovery with neat air. When the cells were exposed to acetylene, a mixture of acetylene in air was injected into the humidified feed stream of the cathode; the humidity of the gas was maintained at a constant level by increasing the temperature setting of the humidifier unit. During constant current testing, AC impedance data from $0.1 \mathrm{~Hz}$ to $10 \mathrm{kHz}$ (10 points per decade) were obtained using a Solartron SI1260 Impedance/Gain-Phase Analyzer and Stanford Research SR560 
Low Noise Preamplifiers with ZPlot ${ }^{\circledR}$ (Scribner Associates) software. An AC current perturbation of $0.75 \mathrm{~A}$, resulting in a voltage change of approximately $5 \mathrm{mV}$, was applied to the single cell at a DC current of $50 \mathrm{~A}$. The load bank cables on the positive and negative sides were equal in length and twisted to reduce system inductance and to improve accuracy. After the acetylene contamination experiment, diagnostics (E0T), CV, LSV and VI were also carried out using the same procedures as for B0T.

\section{Results and discussion}

\subsection{Adsorption of acetylene on MEA electrodes}

\subsubsection{MEA open circuit potential response}

After activation and B0T diagnostics (polarization curve, $\mathrm{H}_{2}$ crossover, and electrochemically active area (ECA) are not shown), the MEA was exposed to $300 \mathrm{ppm}$ acetylene in $\mathrm{N}_{2}$ for different times to study acetylene adsorption and desorption on the electrode. Figure 1 shows the MEA OCP response to a $60 \mathrm{~min}$ acetylene exposure with or without a $30 \mathrm{~min} \mathrm{~N}_{2}$ purge. The spikes in the OCP curves were due to perturbations from water drops in the humidified gas stream lines. The nearly overlapping OCP curves in Figure 1 indicate reproducibility, as the two tests were interrupted at different times to complete the $\mathrm{CV}$ scans. Before exposure, the OCP was $\sim 0.114 \mathrm{~V}$ and is a result of a $\mathrm{H}_{2}$ concentration difference between the sides of the $\mathrm{H}_{2} / \mathrm{N}_{2}$ cell. At the anode, the $\mathrm{H}_{2}$ partial pressure was set at approximately $1 \mathrm{~atm}$; at the cathode, some $\mathrm{H}_{2}$ diffused through the membrane to the cathode side and was diluted by $\mathrm{N}_{2}$. At steady state, the $\mathrm{H}_{2}$ partial pressure can be estimated from the $\mathrm{H}_{2}$ crossover flux and the $\mathrm{N}_{2}$ flow rate at the cathode. The oxidation current density of crossover $\mathrm{H}_{2}$ was $\sim 3.14 \mathrm{~mA} \mathrm{~cm}^{-2}$ as measured by LSV under adsorption operating conditions. The $\mathrm{H}_{2}$ crossover flux was calculated to $1.095 \mathrm{ml} \mathrm{min}^{-1}$ by Faraday's law. The estimated $\mathrm{H}_{2}$ partial pressure at the cathode was approximately $6.6 * 10^{-4} \mathrm{~atm}$. According to the Nernst equation, the OCP of the $\mathrm{H}_{2} / \mathrm{N}_{2}$ cell was $\sim 0.111 \mathrm{~V}$. This calculated result agrees well with the measured OCP. At the beginning of acetylene exposure, the OCP rapidly increased to $0.147 \mathrm{~V}$ in $\sim 1.5 \mathrm{~min}$. During the $60 \mathrm{~min}$ exposure, the OCP slowly decreased and reached a relatively stable value of 0.137 V. According to Farkas and Muetterties, acetylene can be catalytically reduced to ethylene and ethane in the presence of $\mathrm{H}_{2}$ on a Pt 
(111) surface at $80^{\circ} \mathrm{C}[22,23]$. Additionally, acetylene can be electrochemically reduced to ethylene and ethane on a Pt surface under low potentials [24]. The shorted microcells formed by $\mathrm{H}_{2} / \mathrm{C}_{2} \mathrm{H}_{2}$ at the interface between the ionomer film and $\mathrm{Pt} / \mathrm{C}$ in the cathode catalyst layer can result in significant electrochemical reduction of acetylene. The $23-33 \mathrm{mV}$ increase in OCP during acetylene exposure can be attributed to surface reactions between acetylene and crossover $\mathrm{H}_{2}$ and even acetylene adsorption on Pt/C. Possible reactions that can occur include hydrogenation on the Pt (111) surface and electrochemical reductions in microcells that exist in the cathode catalyst layer. The consumption of $\mathrm{H}_{2}$ by acetylene hydrogenation on the cathode side increases the $\mathrm{H}_{2}$ concentration difference between the anode and the cathode, resulting in an increase in the OCP. The standard reduction potential of acetylene to ethylene is $0.731 \mathrm{~V}$, so the electrochemical reduction adsorption of acetylene on the cathode might also create a $\mathrm{H}_{2} / \mathrm{C}_{2} \mathrm{H}_{2}$ cell with a voltage greater than the observed OCP [19, 20]. After acetylene injection was stopped, the OCP decreased to its initial value in $\sim 0.5 \mathrm{~min}$. When the injection was interrupted, no more acetylene remained in cathode, and $\mathrm{H}_{2}$ consumption in the cathode was stopped. The OCP recovered to its initial value. These results indicate that acetylene adsorbed on the MEA electrode either undergoes chemical reaction or electrochemical adsorption, as is expected from acetylene easily adsorbed on Pt surfaces.

\subsubsection{Cyclic voltammetry analysis and acetylene adsorption on MEA electrodes}

To investigate acetylene coverage and electrochemical behaviors of MEA electrodes, CV scanning between 0.08-1.2 V vs HRE was performed after MEA exposures to acetylene in $\mathrm{N}_{2}$ and after pure $\mathrm{N}_{2}$ purges. The $\mathrm{CV}$ curves after a $60 \mathrm{~min}$ acetylene exposure and after a $30 \mathrm{~min}_{2}$ purge are compared to a background $\mathrm{CV}$ measured before acetylene exposure, as shown in Figure 2. The solid line is the overlapped background CVs. Typically, during an anodic sweep, the current peak at $0.15 \mathrm{~V}$ vs HRE and its shoulder at $0.21 \mathrm{~V}$ vs $\mathrm{HRE}$, which ends at $0.4 \mathrm{~V}$ vs $\mathrm{HRE}$, is attributed to $\mathrm{H}_{\mathrm{ad}}$ oxidation/desorption. The current feature described by an onset potential of $0.65 \mathrm{~V}$ vs HRE, a peak at $0.83 \mathrm{~V}$ vs HRE and a plateau beyond the peak is ascribed to Pt oxidation. For the cathodic sweep, the current peak at $0.78 \mathrm{~V}$ vs $\mathrm{HRE}$ is associated with $\mathrm{PtO}_{\mathrm{x}}$ reduction, whereas the negative current rise at $0.35 \mathrm{~V}$ vs $\mathrm{HRE}$ is attributed to $\mathrm{H}$ adsorption and then $\mathrm{H}_{2}$ evolution. The dashed lines are $\mathrm{CV}$ results near the end of the 60 min acetylene exposure. Acetylene injection was continued during the $\mathrm{CV}$ scan. 
The $1^{\text {st }}$ scan, labeled "1," is different from the overlapped $2^{\text {nd }}$ and $3^{\text {rd }}$ scans, labeled " 2 " and " 3, ,", respectively. In the first scan, the $\mathrm{H}_{\mathrm{ad}}$ oxidation feature has almost disappeared due to acetylene adsorption. With an increase in potential, the oxidation current starts to increase at $0.32 \mathrm{~V}$ vs HRE until a peak appears at $0.76 \mathrm{~V}$ vs HRE with a shoulder at $\sim 1.07 \mathrm{~V}$ vs HRE and onset of $0.9 \mathrm{~V}$ vs HRE. According to Wieckowski, the extra current onset of $0.32 \mathrm{~V}$ and peak at $0.76 \mathrm{~V}$ is due to the oxidation of adsorbed ethylene on the Pt surface [25]. As mentioned above, ethylene is the chemical or electrochemical hydrogenation product of acetylene on Pt. The shoulder at $\sim 1.07 \mathrm{~V}$ is attributed to the oxidation of acetylene that re-adsorbs on the Pt surface from bulk gases. In the negative scan, the $\mathrm{PtO}_{\mathrm{x}}$ reduction peak was suppressed, and a current peak appears at $\sim 0.57 \mathrm{~V}$ vs HRE. When the potential is below $0.19 \mathrm{~V}$, the reduction current decreased rapidly to a more negative value. The current peak at $0.57 \mathrm{~V}$ may be attributed to $\mathrm{PtO}_{\mathrm{x}}$ reduction combined with oxidation of reaction products and re-adsorbed acetylene. The significant extra reduction current below $0.19 \mathrm{~V}$ is due to reduction of acetylene re-adsorbed from bulk gases. For the $2^{\text {nd }}$ and $3^{\text {rd }}$ scans, a clear $\mathrm{H}_{2}$ oxidation peak is observed with a reduced area compared to the background value. The $0.72 \mathrm{~V}$ vs HRE oxidation peak and its shoulder at $1.07 \mathrm{~V}$ vs HRE are still present but are less intense. These current peaks are due to the oxidation of ethylene created under low potentials and acetylene re-adsorbed from bulk gases. All current curves overlap in the negative potential scan direction. The dotted line corresponds to CV profiles after a 60 min acetylene exposure followed by a 30 min $N_{2}$ purge. For the $1^{\text {st }}$ scan, the $H_{a d}$ oxidation current is smaller than the background. One small oxidation peak is seen at $\sim 0.58 \mathrm{~V}$ vs HRE; this peak is followed by the typical Pt oxidation feature at higher potentials. During the $\mathrm{N}_{2}$ purge and CV scanning, there was no acetylene in the bulk gases or re-adsorption and hydrogenation of acetylene on the electrode. The small current peak at $0.58 \mathrm{~V}$ is due oxidation of ethylene leftover on the Pt surface from the acetylene exposure. The remainder of the 1st scan overlaps with the last 2 scans, and all features are qualitatively similar to the background scan. Comparing the three series of $\mathrm{CV}$ curves, it can be concluded that acetylene completely covered the electrode, and hydrogenation and desorption of acetylene from the Pt surface can only partially recover the contaminated electrode during the $\mathrm{N}_{2}$ purge. Adsorbed ethylene can be oxidized at high potentials and desorb completely, but acetylene adsorbed above $0.3 \mathrm{~V}$ can only be oxidized above $0.9 \mathrm{~V}$. Acetylene adsorption and 
oxidation at moderate potentials can impact cathode reactions in PEMFCs, likely the reason for ORR effects observed in RRDE investigations [21].

In $\mathrm{H}_{2} / \mathrm{N}_{2}$ cells, the $\mathrm{C}_{2} \mathrm{H}_{\mathrm{x}}(\mathrm{x}=2,4)$ adsorbate coverage on MEA electrodes can be estimated by comparing the $\mathrm{H}_{\mathrm{ad}}$ oxidation charge of the $1^{\text {st }}$ cycle after exposure or after $\mathrm{N}_{2}$ purge to that of B0T scans. The variation of $\mathrm{C}_{2} \mathrm{H}_{\mathrm{x}}$ coverage with acetylene exposure and $\mathrm{N}_{2}$ purge time is shown in Figure 3. With increasing exposure time, $\mathrm{C}_{2} \mathrm{H}_{\mathrm{x}}$ coverage on the electrode increases. After exposure for approximately $60 \mathrm{~min}$, the electrode was almost completely covered by $\mathrm{C}_{2} \mathrm{H}_{\mathrm{x}}$ adsorbates. When the acetylene injection was stopped, the coverage decreased rapidly within a minute due to the hydrogenation and desorption of acetylene. However, after an $\mathrm{N}_{2}$ purge for approximately 30 min, the coverage reached a stable value of $\sim 60 \%$; longer $\mathrm{N}_{2}$ purges could not further reduce coverage. The $\mathrm{C}_{2} \mathrm{H}_{\mathrm{x}}$ adsorption states with different electrode coverages can also be analyzed by comparing changes in $\mathrm{H}_{\mathrm{ad}}$ oxidation charges to oxidation charges within 0.32 to $1.2 \mathrm{~V}$ between cycles [19]. For CVs during acetylene exposures, the oxidation charges of $\mathrm{H}_{\mathrm{ad}}$ or $\mathrm{C}_{2} \mathrm{H}_{\mathrm{x}}$ adsorbates of $1^{\text {st }}$ anodic scan, $Q_{H, o x}^{1}$ or $Q_{H C, o x}^{1}$ could not be calculated accurately due to re-adsorption of acetylene from bulk gases. However, the overlapped cathodic curves and the repeatable subsequent scans suggested that the pre-adsorbed acetylene species could be completely oxidized by the first anodic scanning, releasing the electrode surface for subsequent additional hydrogen adsorption. Additionally, acetylene re-adsorption was repeatable and equivalent for all CV cycles. The average number of charges per adsorption site $n$ can be estimated from anodic charges with the following equation [19]:

$$
n \approx \Delta Q_{H C, o x} / \Delta Q_{H, o x}=\left(Q_{H C, o x}^{1}-Q_{H C, o x}^{2}\right) /\left(Q_{H, o x}^{2}-Q_{H, o x}^{1}\right)
$$

Where 1 and 2 are cycle numbers of the CV scan. The variation of average charge number with exposure time and $\mathrm{C}_{2} \mathrm{H}_{\mathrm{x}}$ adsorbate coverage is shown in Figure 3. After a 10 min exposure, $\mathrm{C}_{2} \mathrm{H}_{\mathrm{x}}$ adsorbates covered $\sim 60 \%$ of Pt surface, and the corresponding average charges number was 4.7 per adsorption site. Because the electro-oxidation of each $\mathrm{C}_{2} \mathrm{H}_{\mathrm{x}}$ species requires 10 or 12 electrons, the number of Pt sites blocked by each $\mathrm{C}_{2} \mathrm{H}_{\mathrm{x}}$ is 2.1-2.5. When the electrode was fully covered, i.e., after a 30 min exposure, the average charge number was 10.5 , and each $\mathrm{C}_{2} \mathrm{H}_{\mathrm{x}}$ species only occupies one Pt site. These results agree well with the literature [19]. The adsorbed species were di- $\sigma$-bonded $\mathrm{C}_{2} \mathrm{H}_{\mathrm{x}}$ 
and $\pi$-bonded $\mathrm{C}_{2} \mathrm{H}_{\mathrm{x}}$ at low and high coverages, respectively [26]. After $\mathrm{N}_{2}$ purges for various times, the average charge numbers were always approximately 4 , indicating that each $\mathrm{C}_{2} \mathrm{H}_{\mathrm{x}}$ species covered 2.5-3 Pt sites. The adsorbate might be the stable surface species ethylidyne, which has been confirmed to be an adsorption product of acetylene and ethylene on the Pt surface [27]. In the $\mathrm{H}_{2} / \mathrm{N}_{2}$ cell, the di- $\sigma$-bonded and $\pi$-bonded $\mathrm{C}_{2} \mathrm{Hx}$ was readily reduced to methane by crossover $\mathrm{H}_{2}$ and then desorbed; but the adsorbed ethylidyne could not be reduced and remained on the Pt surface. During CV scanning, the leftover ethylidyne was oxidized with a current peak at $0.58 \mathrm{~V}$, as shown in Figure 2.

These results indicate that acetylene can readily adsorb on the MEA electrode as expected, and the reactions are complicated and strongly dependent on electrode surface states. Reduction and desorption are rapid with presence of $\mathrm{H}_{2}$ adsorption, but oxidation/desorption are difficult when the cathode potential is lower than $1 \mathrm{~V}$. The cathode potential of an operating PEMFC is much lower than $1 \mathrm{~V}$ but higher than that required for $\mathrm{H}_{2}$ adsorption. Additionally, previous RRDE results suggested that acetylene adsorption on Pt enhances the production of the peroxide ORR intermediate within the potential range of $0.05-0.70 \mathrm{~V}$ vs HRE [21]. This situation suggests that acetylene may negatively impact the cathodes of PEMFCs.

\subsection{Acetylene contamination in operating PEMFCs}

\subsubsection{Cell performance degradation and recovery}

After activation and B0T diagnostics of a new MEA, acetylene contamination was investigated in an operating PEMFC using a three-phase experiment. Figure 4 shows the cell voltage and the degradation rate (the derivative of the cell voltage over time, $\partial \mathrm{V} / \partial \mathrm{t}$, inset) response to $300 \mathrm{ppm}$ acetylene at a temperature of $80{ }^{\circ} \mathrm{C}$ and a current density of $1 \mathrm{~A} \mathrm{~cm}^{-2}$. For the first 5 hours under neat $\mathrm{H}_{2}$ /Air operation, the MEA exhibited a steady cell voltage (approximately $0.677 \mathrm{~V}$ ). When the cell was exposed to acetylene, two stages are likely involved in the degradation of cell voltage. At the beginning of the exposure, the cell voltage dropped approximately $30 \mathrm{mV}$ within $2 \mathrm{~min}$. Next, a slow transient degradation was followed by a second rapid decrease. After approximately 30 min of exposure (5.67 hours into the experiment), the cell voltage decreased to $0.178 \mathrm{~V}$, and the degradation slowed once again. Then, the cell voltage reached a steady state of approximately $0.083 \mathrm{~V}$ in $20 \mathrm{~min}$. 
At the end of a 5-hour acetylene exposure, the cell voltage decreased slightly, reaching $0.08 \mathrm{~V}$. This final poisoned state represents an approximately $88 \%$ loss in cell performance. The cell voltage degradation rate (inset of Figure 4) showed two peaks with values of -1.27 and $-6.38 \mathrm{~V} \mathrm{hr}^{-1}$ at 5.17 and 5.66 hours, respectively. The inflection point between the two peaks occurred at $\sim 5.2$ hours and divided the cell voltage degradation curve into two stages. The cell voltage at the inflection point was approximately $0.648 \mathrm{~V}$. When the acetylene injection was stopped, the cell voltage increased immediately. The recovery of cell voltage also included two stages, and these two stages may correspond to the two stages of degradation. Within the first 2 min of recovery, the cell voltage increased to $0.639 \mathrm{~V}$, restoring over $94 \%$ of the original cell performance. The voltage recovery then slowed, reaching a steady value of $0.677 \mathrm{~V}$ after approximately 5 hours of recovery; this final cell voltage represents complete recovery of cell performance. The cell voltage responses of the contamination experiment indicated that acetylene in the MEA cathode can cause significant losses in cell performance. Additionally, both the contamination and recovery processes include at least two different processes. However, this performance loss can be completely self-restored after switching to neat air operation.

According to the literature, the adsorption/reactions of acetylene on Pt surfaces are dependent on potential. Acetylene on Pt surfaces can be electro-oxidized to $\mathrm{COH}$-type intermediates at potentials higher than $0.35 \mathrm{~V}$ vs RHE and then further oxidized to $\mathrm{CO}_{2}$ at potentials higher than $0.70 \mathrm{~V}$ vs RHE or electro-reduced to ethylene and ethane at potentials lower than $0.2 \mathrm{~V}$ vs RHE in a sulfuric acid solution [19]. In operating MEAs, oxygen can also chemically oxidize acetylene to CO, which subsequently either desorbs or is further oxidized to $\mathrm{CO}_{2}[15,16]$. The cell voltage responses to acetylene exposure in Figure 4 may be explained by competition between the ORR, chemical reactions involving acetylene and oxygen, and electro-oxidation of acetylene on the Pt surface. As mentioned above, before exposure to acetylene, cell voltages were $0.677 \mathrm{~V}$. The ohmic resistance of the MEA, which was measured by AC impedance, was approximately $0.052 \Omega \mathrm{cm}^{2}$. Considering the ohmic polarization of the MEA (approximately $0.052 \mathrm{~V}$ ) and disregarding the hydrogen oxidation overpotential at the anode, the cathode potential is at least $0.729 \mathrm{~V}$ vs RHE. At this potential, the $\mathrm{COH}$-type intermediates and $\mathrm{CO}$ can be electro-oxidized to $\mathrm{CO}_{2}$ by Pt-OH. When the cathode is 
exposed to acetylene, competition between acetylene oxidation and the ORR immediately caused a slightly performance loss $(30 \mathrm{mV})$ at the first stage within the first 2 min of exposure. The $\mathrm{CO}$ and $\mathrm{COH}$ intermediates might accumulate on the Pt surface due to the slow electro-oxidation of $\mathrm{CO}$ and $\mathrm{COH}$ intermediates on Pt surfaces at pre-peak potentials $[28,29]$. This accumulation of intermediates inhibits the ORR and increases the ORR overpotential at the cathode. The slow voltage decrease during the transient period from $\sim 5.18$ to $\sim 5.4$ hours was a result of the initial accumulation of CO and $\mathrm{COH}$ intermediates on the $\mathrm{Pt}$ surface, which facilitated further intermediate accumulation. The accumulation of intermediates and degradation of cell voltage coordinate with and promote each other, as shown in the cell voltage degradation rate curve before the second peak. The second rapid drop in cell voltage then occurred due to acetylene adsorption, creating the second degradation rate peak. When the cell voltage decreased to $0.178 \mathrm{~V}$, resulting in a cathode potential of approximately $0.23 \mathrm{~V}$ vs RHE, crossover $\mathrm{H}_{2}$ can deposit on $\mathrm{Pt}$ surface. The adsorbed acetylene can be electro-reduced to ethylene and ethane, which can easily desorb [23, 24]. Reduction may dominate the acetylene reactions on the $\mathrm{Pt}$ surface. The adsorption, reaction and desorption of oxygen, acetylene and their products reached a dynamic equilibrium resulting in stable adsorbate coverages and a steady state cell voltage. After discontinuing the acetylene injection, the adsorbed acetylene might be continuously reduced and desorb, releasing most of the Pt sites to the ORR reaction. This release corresponds to the first stage of voltage recovery. The cell voltage recovered to $0.639 \mathrm{~V}$ within approximately $2 \mathrm{~min}$. However, some $\mathrm{CO}$ and $\mathrm{COH}$ intermediates, acetylene, and even adsorbed ethylidyne remain on the $\mathrm{Pt}$ surface, and these intermediates must be oxidized and/or desorb slowly until no intermediates remain. This second recovery stage was completed slowly after five hours of operation with neat air.

\subsubsection{Electrochemical Impedance Spectroscopy Analysis}

During the three-phase acetylene contamination experiments, the AC impedance responses of the MEAs were collected to determine the impact of acetylene on the electrochemical reactions in the MEAs. Figures 5 shows representative impedance spectra in Nyquist plots for each phase of the acetylene contamination experiments. Before exposure to acetylene, the response of both MEAs shows a typical EIS at high current densities, characterized by three distinguishable depressed semicircles [30]. The value of approximately $0.052 \Omega \mathrm{cm}^{2}$ at the intersection of the EIS with the Re 
(Z) axis at high frequencies represents the serial ohmic resistance of proton and electron transport in the bulk system. The high frequency $(>1 \mathrm{kHz})$ response can be attributed to the hydrogen oxidation reaction (HOR), the midrange frequency $(5 \mathrm{~Hz}-1 \mathrm{kHz})$ response to the ORR, and the low frequency $(0.1 \mathrm{~Hz}-5 \mathrm{~Hz})$ response to mass transport in the gas diffusion electrode (GDE). During exposure to acetylene, the mid and low frequency arcs in the EIS at the steady poisoning state (1.5 hr and $4.5 \mathrm{hr}$ ) merged together and were significantly expanded compared to the arcs before exposure. There was also an additional inductive loop at low frequencies, which is similar to the response of the HOR to CO contamination at the PEMFC anode [31]. The significant charge transfer effect indicates severe loss of electrode ECA due to coverage by acetylene intermediates. These changes indicated that the adsorption of acetylene in MEA dramatically affects cathode charge transfer and may also affect mass transport of oxygen in the MEA [32]. The inductive loop at low frequencies may be attributed to the impact of AC perturbations on Pt surface coverage. A small perturbation could noticeably affect the coverage of acetylene intermediates due to the rapid reduction of acetylene on the Pt surface. This mechanism needs more study and will be analyzed in future work. After self-recovery, the EIS overlapped the pre-exposure EIS as shown in the inset, suggesting complete recovery of the MEA. These EIS results revealed the effect of acetylene contamination on the ORR in the PEMFC cathode.

\subsubsection{MEA Performance diagnostics-CV, LSV and VI}

After the acetylene contamination experiment, diagnostics (E0T) were performed using the same procedures as for B0T to determine the influence of acetylene contamination on the MEAs. CV scanning was used to analyze possible intermediate residues on the Pt surface and to obtain any additional recovery in MEA performance after self-recovery. Figure 6 shows CV profiles of the cathodes before and after the acetylene contamination experiment. From the figure, it can be seen that the curves before and after the experiment nearly overlap each other and show features typical of Pt/C in a CCM. After the acetylene contamination experiment, the hydrogen oxidation/reduction current peaks within a potential range of $0.10-0.40 \mathrm{~V}$ appear to shrink slightly. The onset of the Pt oxidation current shifted to a positive potential, while the Pt-oxide reduction current peaks decreased slightly. The ECAs calculated from the hydrogen reduction current peak (the shadowed part in Figure 6) are

$\sim 64.1$ and $\sim 59.3 \mathrm{~m}^{2} \mathrm{gPt}^{-1}$ before and after the acetylene contamination experiment, respectively. This 
slight catalyst degradation of approximately $7 \%$ ECA can be attributed to general aging, which includes processes such as dissolution and agglomeration of $\mathrm{Pt}$ particles under regular operation [5]. After recovery, no other redox current peaks were observed in the profiles for either exposure experiments after neat air operation. These results indicate that no contaminant residue remains on the $\mathrm{Pt} / \mathrm{C}$ surface and confirm complete recovery of the cathode electrode.

Hydrogen crossovers of the MEAs were detected by LSV before and after the acetylene contamination experiment. The oxidation current densities of hydrogen through the MEAs were used to calculate the hydrogen crossover. The current density curves almost overlap each other at $\sim 0.87 \mathrm{~mA} \mathrm{~cm}^{-2}$. These results suggest that both MEAs had similar permeabilities and that acetylene contamination had no obvious effect on permeability.

The polarization curves and the HFR of the MEAs were collected from $2 \mathrm{~A} \mathrm{~cm}^{-2}$ to OCV before and after acetylene contamination experiments. Figure 7 shows the VI (Voltage) and HFR-corrected (IRVoltage) curves, and the inset depicts HFR-corrected VI curves in log scale. Comparing the two pairs of VI curves, the voltage differences are less than $10 \mathrm{mV}$ when the current density is lower than $0.8 \mathrm{~A} \mathrm{~cm}^{-2}$; at current densities higher than $0.8 \mathrm{~A} \mathrm{~cm}^{-2}$, the VI curves almost overlap each other. The inset depicts the kinetic region of the VI curve in Tafel coordinates at current densities of 0.01 to $0.1 \mathrm{~A} \mathrm{~cm}^{-2}$. Both VI curves show similar Tafel slopes of $\sim 63 \mathrm{mV}$ per decade, which confirms the absence of contaminant adsorbate on the electrode surface. The $7 \pm 2 \mathrm{mV}$ difference between the two curves is partially attributed to the $7 \%$ ECA loss. These results imply that no obvious activation, ohmic polarization or mass transport effect remains on the MEAs after neat air operation and confirm complete recovery.

\section{Conclusions}

The adsorption of acetylene, an airborne contaminant, on the electrode of a PEMFC was studied in a humidified $\mathrm{H}_{2} / \mathrm{N}_{2}$ cell, and the impact on cell performance was investigated with 300 ppm acetylene in the cathode at $80{ }^{\circ} \mathrm{C}$. Electrochemical characterizations indicated that acetylene adsorbs readily on electrodes and is reduced to ethylene and ethane at low potentials and electro-oxidized at high potentials. Injection of $300 \mathrm{ppm}$ acetylene at the cathode of an operating PEMFC results in a cell 
performance loss of approximately $88 \%$. Acetylene contamination processes may include acetylene oxidation and reduction as well as accumulation of intermediates on the electrode surface. The oxidation intermediates, such as $\mathrm{CO}$ and/or $\mathrm{COH}$-type adsorbates can accumulate on the Pt surface and cause additional cell performance losses. EIS analysis demonstrated competition between acetylene reactions and ORR on the Pt surface as well as accumulation of intermediates. Fortunately, cell performance loss can be recovered completely with neat air operation for several hours without any remaining contaminant residue in the MEA. These observations have prompted additional studies that will be reported at a future time. Adsorbed contaminants lead to larger rates of peroxide production which are detectable with a rotating ring/disc electrode [21]. Gas chromatography/mass spectroscopy analyses will confirm the proposed acetylene reaction products. The mass transport influence is also expected to be clarified with residence time distribution and segmented cell measurements. Finally, operating conditions are expected to influence acetylene contamination, which is an important concern for the operation of fuel cell systems including startup and duty cycling.

\section{Acknowledgments}

The authors are indebted to the United States Department of Energy for funding (award DE-EE0000467). The authors are also grateful to the Hawaiian Electric Company for their ongoing support to the operations of the Hawaii Sustainable Energy Research Facility. 


\section{References}

[1] M.K. Debe, Nature 486 (2012) 43-5.

[2] Y. Garsany, O.A. Baturina, K.E. Swider-Lyons, J. Electrochem. Soc. 154 (2007) B670-B675.

[3] Z. Ma, F. Zaera, Surf. Sci. Rep. 61 (2006) 229-281.

[4] J. St-Pierre, Air impurities, in: Büchi FN, Inaba M, Schmidt TJ (Eds.), Polymer electrolyte fuel cell durability, Springer, New York, 2009, pp. 289-321.

[5] R. Borup et al, Chem. Rev. 107 (2007) 3904-3951.

[6] X. Cheng, Z. Shi, N. Glass, L. Zhang, D. Song, Z. Liu, H. Wang, J. Shen, J. Power Sources 165 (2007) 739-756.

[7] J.M. Moore, P.L. Adcock, J.B. Lakeman, G.O. Mepsted, J. Power Sources 85 (2000) 254-260.

[8] http://www.epa.gov/airquality/airdata/index.html.

[9] R. Mohtadi, W.K. Lee, J.W. Van Zee, J. Power Sources 138 (2004) 216-225.

[10] H. Li, J. Zhang, Z. Shi, D. Song, K. Fatih, Sh. Wu, H. Wang, J. Zhang, N. Jia, S. Wessel, R. Abouatallah, N. Joos, J. Electrochem. Soc. 156 (2009) B252-B257.

[11] M.C. Smith, D.J. Myers, 211th ECS meeting, Abs.0214.

[12] J. St-Pierre, M.S. Angelo, Y. Zhai, Electrochem. Soc. Trans. 41(1) ( 2011) 279-286.

[13] J. St-Pierre, Y. Zhai, M.S. Angelo, J. Electrochem. Soc. 161(3) (2014) F280-F290.

[14] R.M. Patterson, M.I. Bornstein, E. Garshick, Assessment of Acetylene [etc.] as a Potential Air Pollution Problem: Final Report, for U.S. Environmental Protection Agency, GCA Corporation, Technology Division, 1976.

[15] D.J. Burnett, A.M. Gabelnick, D.A. Fischer, A.L. Marsh, J.L. Gland, J. Catal. 230 (2005) 282-290.

[16] C.E. Megiris, P. Berlowitz, J.B. Butt, H.H. Kung, Surf. Sci. 159(1) (1985) 184-198.

[17] M. Rashidi, R. J. Puddephatt, J. Am. Chem. Soc. 108(22) (1986) 7111-7112.

[18] O. Nakagoe, N. Takagi, Y. Matsumoto, Surf. Sci. 514(1-3) (2002) 414-419.

[19] A.B. Delgado, A.M. Castro Luna, W.E. Triaca, A.J. Arvía, J. Electrochem. Soc. 129(7) (1982) 1493-1498.

[20] J.W. Johnson, H. Wreblowa, J.O'M. Bockris, J. Electrochem. Soc. 111(7) (1964) 863-870. 
[21] J. Ge, J. St-Pierre, Y. Zhai, Electrochim. Acta. 133 (2014) 65-72.

[22] E. Muetterties, M. Tsai, S. Kelemen, Proc. Natl. Acad. Sci. USA 78 (1981) 6571-6575.

[23] A. Farkas, L. Farkas, J. Am. Chem. Soc. 61 (1939) 3396-3401.

[24] M. Byrne, A.T. Kuhn, V.J. Whittle, J. Chem. Soc., Faraday Trans. 169 (1973) 787-793.

[25] A. Wieckowski, S. Rosasco, G. Salaita, A. Hubbard, B. Bent, F. Zaera, D. Godbey, G. Somorjai, J . Am. Chem. Soc. 107 (1985) 5910-5920.

[26] J. Kua, W.A. Goddard III, J. Phys. Chem. B 102 (1998) 9492-9500.

[27] L.L. Kesmodel, L.H. Dubois, G. A. Somorjai, J. Chem. Phys. 70 (1979) 2180-2188.

[28] S. Balasubramanian, B. Lakshmanan, C.E. Hetzke, V.A. Sethuraman, J.W. Weidner, Electrochim. Acta. 58 (2011) 723-728.

[29] F. Maillard, E.R. Savinova, U. Stimming, J. Electroanal. Chem. 599 (2007) 221-232.

[30] Y. Zhai, K. Bethune, G. Bender, R. Rocheleau, J. Electrochem. Soc. 159 (2012) B524-B530.

[31] M. Ciureanu, H. Wang, Zh. Qi, J. Phys. Chem. B 103 (1999) 9645-9657.

[32] J. St-Pierre, J. Ge, Y. Zhai, T. V. Reshetenko, M. Angelo, Electrochem. Soc. Trans. 58 (1) (2013) 519-528. 


\section{Figure captions:}

Figure 1: OCP response to acetylene adsorption on an MEA electrode in the $\mathrm{H}_{2} / \mathrm{N}_{2}$ mode. (Colors online)

Figure 2: CVs obtained near the end of MEA exposure to acetylene in $\mathrm{N}_{2}$ and after a subsequent pure $\mathrm{N}_{2}$ purge (Figure 1). 1, $1^{\text {st }}$ cycle; $2,2^{\text {nd }}$ cycle; $3,3^{\text {rd }}$ cycle. (Colors online)

Figure 3: Variation of acetylene coverage and charge number per adsorption site with exposure time. (Colors online)

Figure 4: Cell voltage and degradation rate responses to $300 \mathrm{ppm}$ acetylene in the air stream of PEMFCs under $1 \mathrm{~A} \mathrm{~cm}^{-2}$ at $80^{\circ} \mathrm{C}$. (Colors online)

Figure 5: EISs before, during and after the MEA cathode is exposed to $300 \mathrm{ppm}$ acetylene. (Colors online)

Figure 6: $\mathrm{CV}$ profiles of MEAs before and after $300 \mathrm{ppm}$ acetylene contamination and neat air recovery. (Colors online)

Figure 7: Polarization and HFR-corrected polarization curves of the MEA before and after acetylene contamination and neat air recovery. (Colors online) 


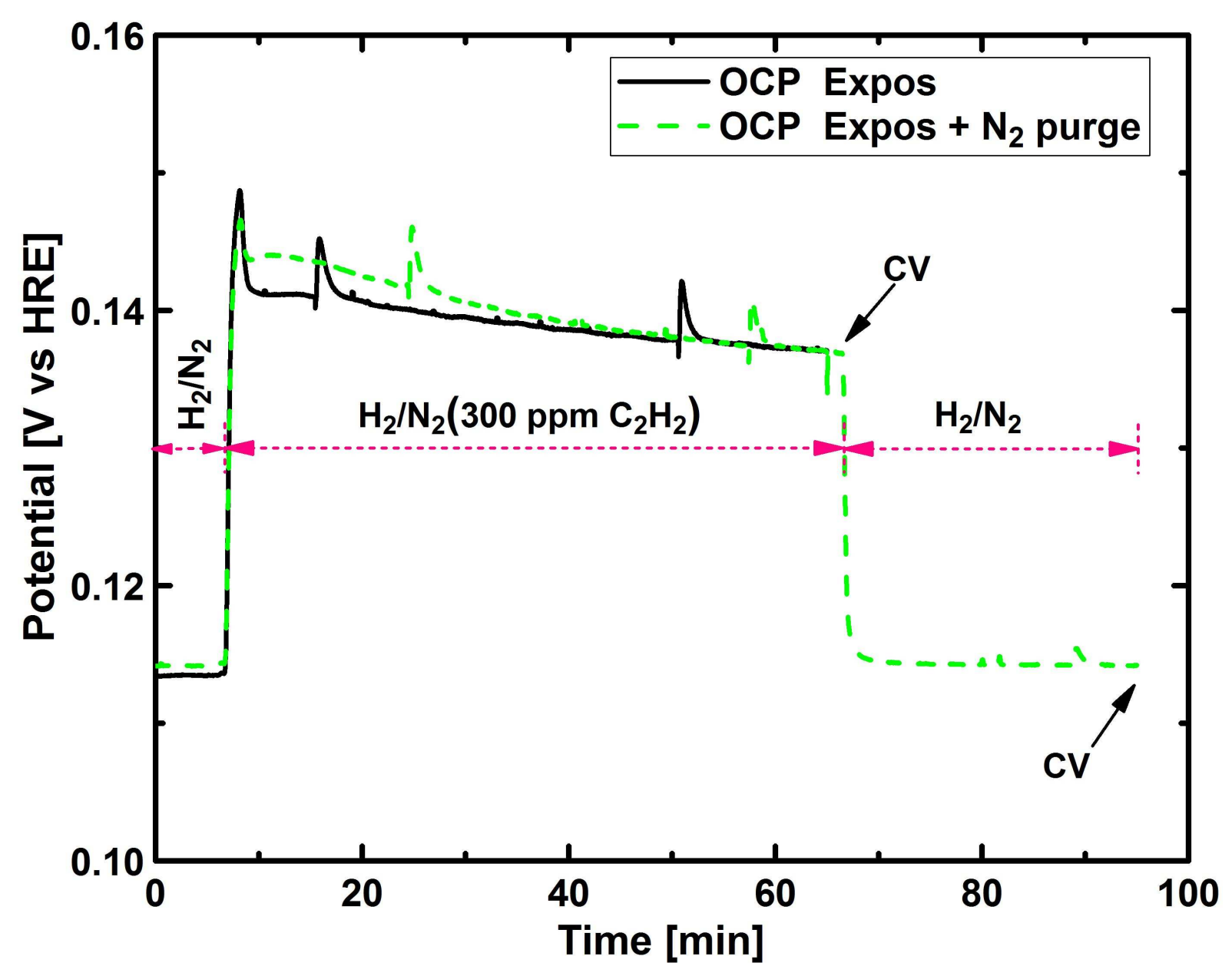




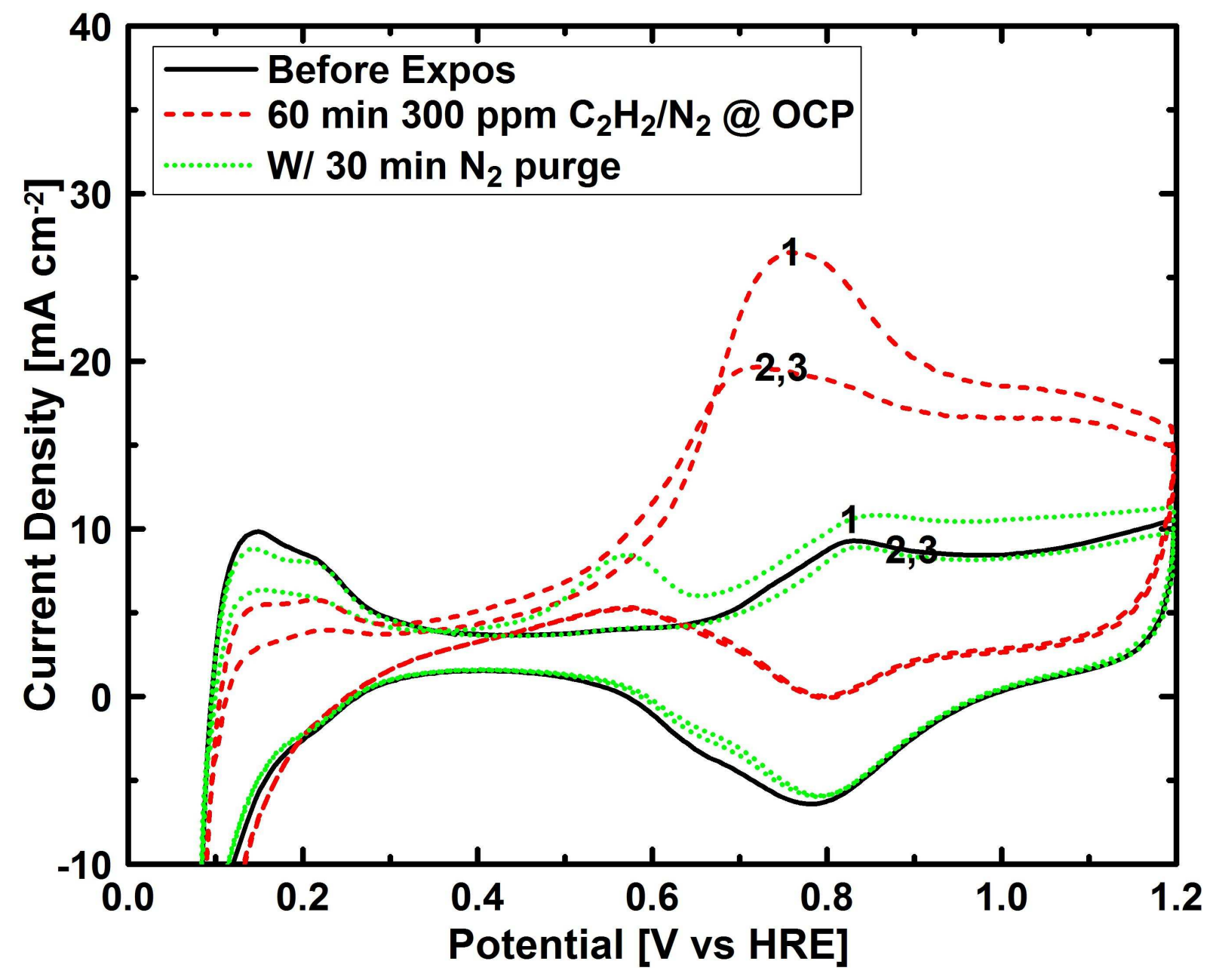




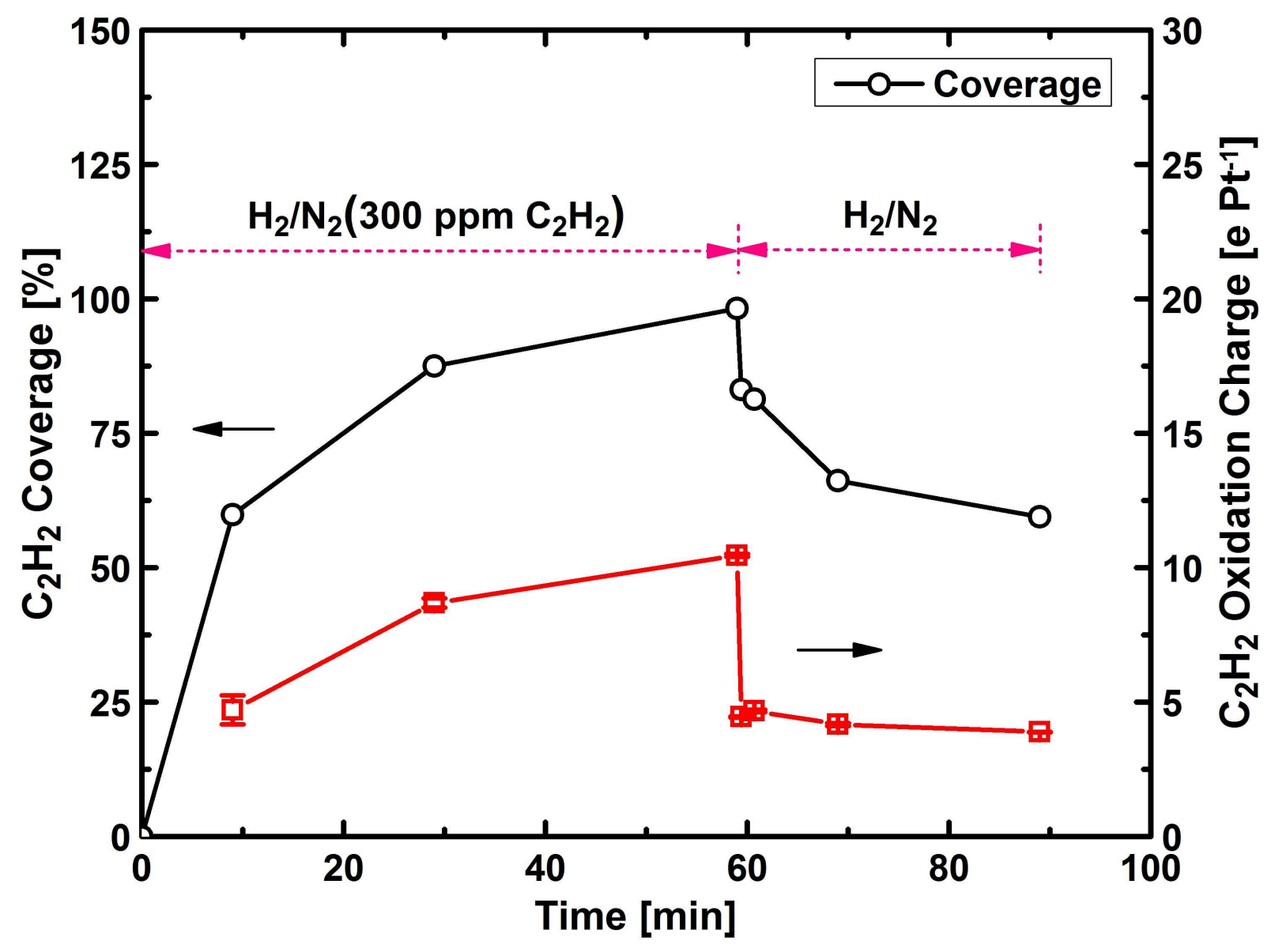




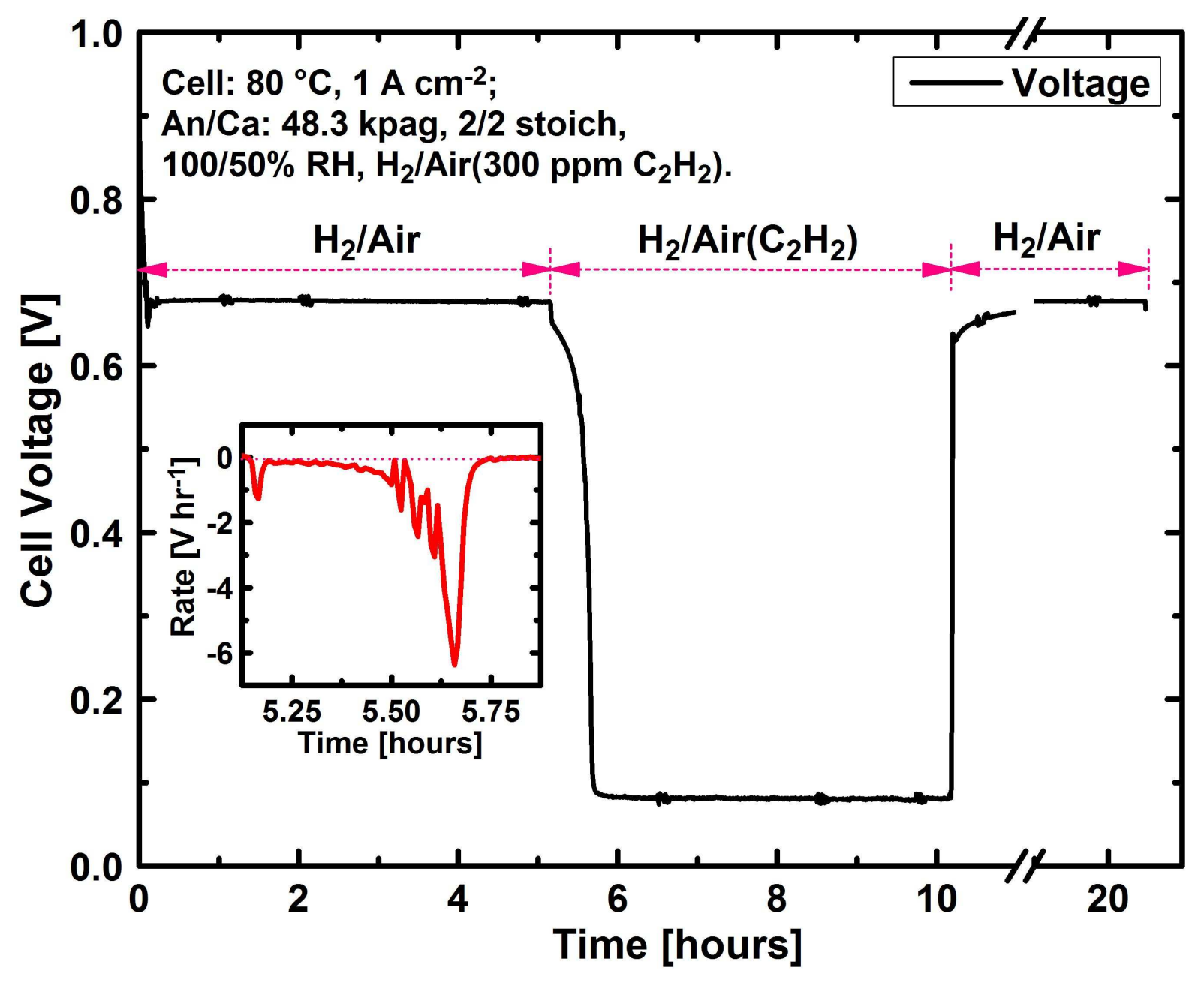




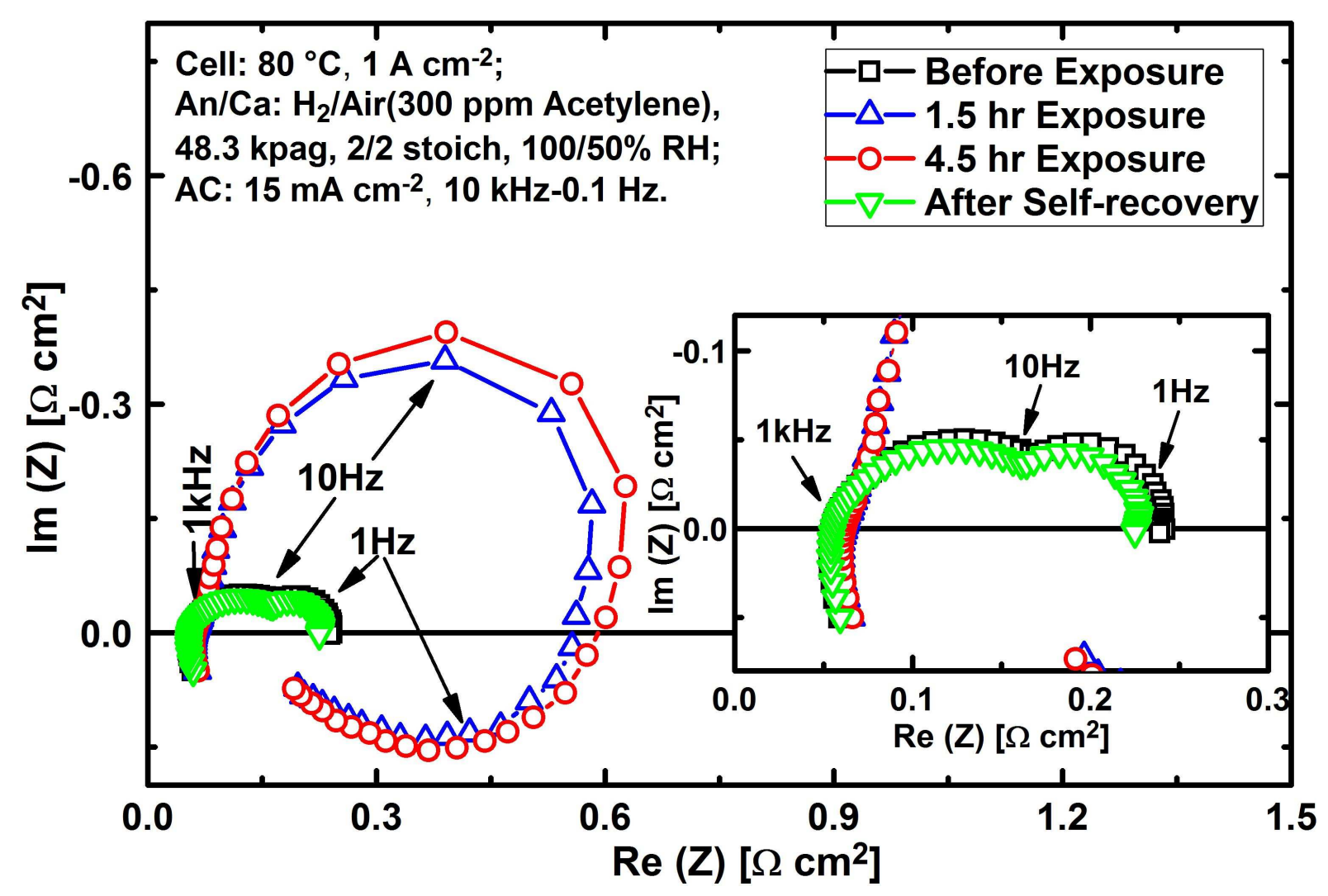




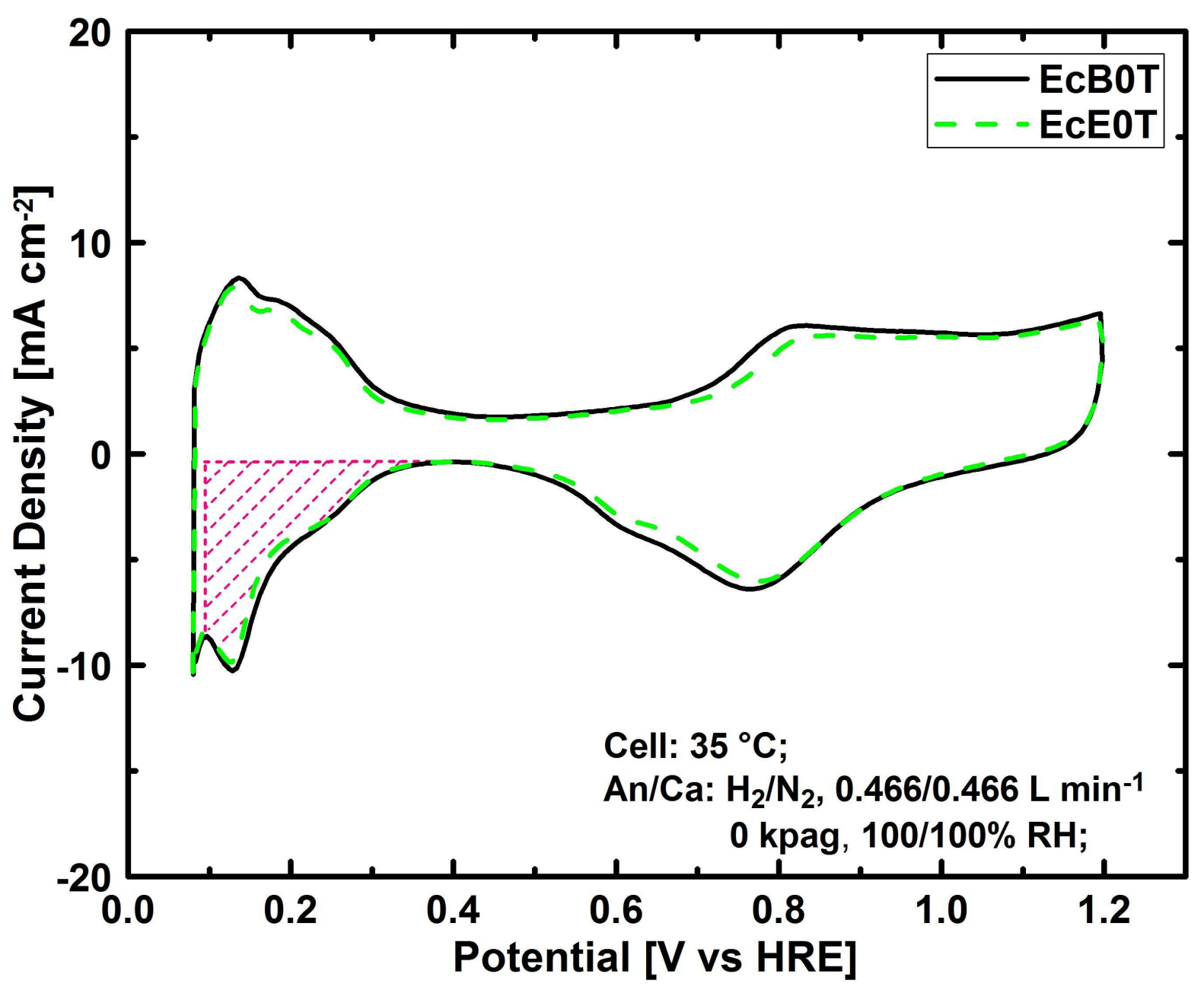




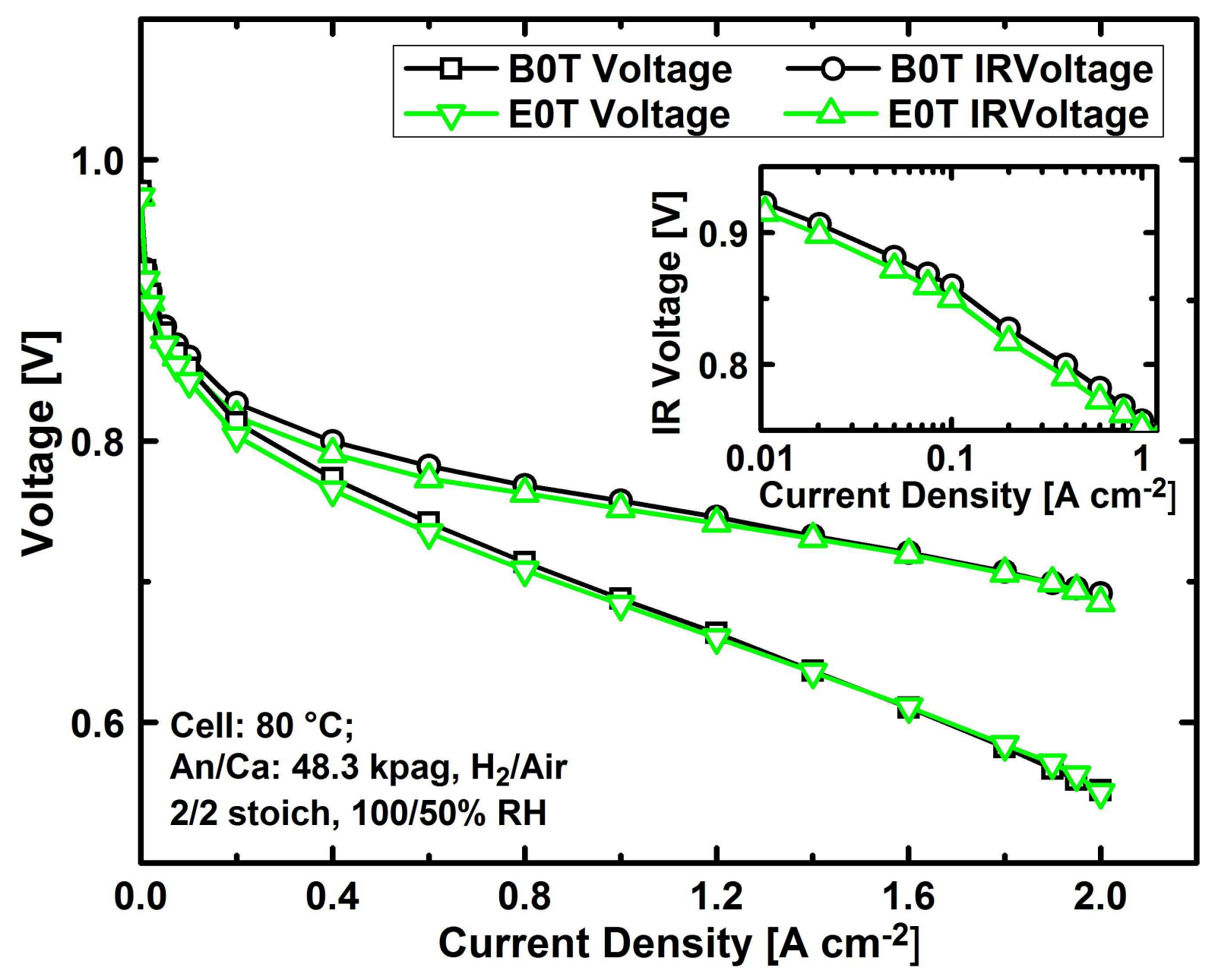

